\title{
PEMBELAJARAN TAJWID DAN TAHSIN AL-QUR'AN DENGAN METODE QIRA'ATI DI RUMAH BELAJAR MAHASISWA KKN DESA HAMBUKU HULU
}

\author{
Ridhatullah Assya'bani, Anita Sari, Elfa Hafizah, Faizatul Hasanah, Marniyah
}

Sekolah Tinggi Ilmu al-Qur'an (STIQ) Amuntai

\begin{abstract}
Abstrak
Penelitian ini dilatarbelakangi oleh banyaknya anak-anak pada saat sekarang ini, khususnya pada daerah perdesaan, dimana masib terdapat anak yang belum bisa membaca Al Qur'an sesuai ilmu tajwid dan tabsin. Kalau sejak dini masib belum mampu membaca Al-Qur'an menggunakan ilmu tajwid dan tahsin, maka akan sulit juga ketika besar memahami bukum-bukum bacaan yang ada didalam Al-Qur'an. Maka dari itu banyak orangtua menitipkan anaknya ke Taman Pendidikan Al-Quran (TPA) untuk belajar agama, khususnya cara membaca Al-Quran. Namun hal ini masih saja belum optimal dikarenakan sebagian Guru disana tidak menerapkan pembelajaran ilmu tajwid dan tabsin, maka dengan demikian, dibangunlah sebuah rumah belajar mahasiswa KKN yang disana mereka mengajarkan sebuab pembelajaran tajwid dan tahsin. Yaitu memakai suatu metode untuk memudabkan anak di dalam membaca Alquran, yaitu metode Qi ro ati. Tujuan dari penelitian ini untuk mengetahui implementasi metode Qiroati, serta faktor yang menjadi penunjang dan penghambat pembelajaran membaca Alquran. Jenis penelitian ini menggunakan jenis penelitian kualitatif. Teknik pengumpulan data menggunakan observasi. Teknik analisis data yang digunakan adalah dengan deskriptive interpretative. Hasil penelitian menunjukkan babwa pada metode Qiroati mampu diterapkan di desa tersebut, karena dengan menggunakan metode ini mampu menarik anak-anak untuk rajin membaca Al-Qur'an dan juga agar anak tidak merasa bosan ketika belajar membaca Al-Quran. Faktor yang menjadi penunjang di dalam pembelajaran Alquran yaitu (a) Tempat; dan (b) Media Pembelajaran Kemudian faktor yang menjadi pengahambatnya yaitu (a) Orangtua; dan (b) minat dan motivasi anak (c) saran dan prasrana
\end{abstract}

Kata kunci: implementasi, metode Qiroati, membaca Alquran.

\section{PENDAHULUAN}

Sebagai seorang muslim, hal utama yang harus dipelajari adalah tentang kitab sucinya sendiri, yaitu Alquran. Pendidikan Al-Qur'an adalah pendidikan paling utama yang harus diajarkan kepada setiap manusia. Baik itu untuk dirinya sendiri, keluarga, 
teman, maupun yang lainnya. ${ }^{1}$ Sebagaimana pernyataan tersebut, maka telah kita ketahui bersama bahwa pembelajaran Al-Qur'an itu sangatlah penting. Begitu juga dengan membaguskan bacaannya karena. Dalam membaca ayat-ayat suci Al-Qur'an itu bukan hanya sekedar membaca. Melainkan juga harus sesuai dengan kaidah ilmu tajwid, dalam artian wajib membaca Al-Qur'an dengan bertajwid. Dalam istilah lain disebut dengan tartil. Sebagaimana tutnunan yang terdapat dalam Q.S. Al-Muzammil ayat 4, yang artinya:

"... Dan bacalah Al-Qur'an dengan tartil “.

Selain ayat Al-Qur'an diatas, perintah membaca Al-Qur'an dengan bagus, baik dan benar juga disabdakan Rasulullah SAW yang artinya: "Hiasilah Alquran dengan suara kalian". (HR. Ahmad, Ibnu Majah, dan An- Nasai). ${ }^{2}$

Adapun di desa yang kami tempati selama masa KKN sesuai survei yang kami lakukan kurang lebih dalam kurun waktu 1 bulan ini, maka terdapat beberapa masalah yang kami dapati selama berKKN di Desa Hambuku Hulu ini. Diantara beberapa masalah yang kami dapati yaitu, yang pertama kurangnya fasilitas untuk membaca alQur'an sehingga proses belajar -mengajar sedikit terhambat, yang kedua minimnya guru yang mengajar Al-Qur'an di desa tersebut mengingat faktor pandemi ini maka juga berimbas pada proses pendidikan Al-Qur'an. Hal ini dikarenakan sistem perekonomian juga ikut merosot selama pandemi, jadi sebagian masyarakatnya banyak yang sibuk untuk menjalani rutinitas mata pencaharian mereka, diantaranya bertani, berkebun dan mengerjakan kerajinan tangan seperti menganyam bakul dari rotan/lupu. Sedangkan jumlah anak-anak di desa Hambuku Hulu ini sangatlah banyak.

Yang ketiga adalah sistem pembelajaran atau metode yang digunakan masih seadanya atau metode tradisional. Keseringan hanya memakai metode Iqro' saja. Jadi, mengingat beberapa permasalahan tersebut maka kami mencoba berinprovisasi dengan menggunakan metode yang belum pernah diterapkan oleh guru-guru Al-

\footnotetext{
${ }^{1}$ Ramayulis, Ilmu Pendidikan Islam (Jakarta, 2012), hal.31.

2 Abu Bakar Jabir al-Jaza 'iri, Minhajul Muslim:.Konsep Hidup Ideal dalam Islam (Jakarta: Darul Haq, 2011), hal.190.
} 
Qur'an disini. Mengingat kebanyakan guru-guru disini adalah mereka yang sudah sepuh (kakek-kakek dan nenek-nenek). Atas dasar ini lah kami menguji cobakan metode Qiroati yang diimplementasikan dalam proses Pembelajaran Tajwid dan Tahsin di Rumah Belajar KKN Desa Hambuku Hulu.

\section{A. METODE PELAKSANAAN}

1. Tujuan Kegiatan

Kegiatan ini dirancang untuk memenuhi tugas masa pengabdian masyarakat yaitu Kuliah Kerja Nyata (KKN) yang diseleggarakan pihak kampus Sekolah Tinggi Ilmu Al-Qur'an (STIQ) Amuntai dalam kurun waktu kurang lebih selama 1 bulan saja. Adapun tujuan dari kegiatan pembelajaran tajwid dan tahsin ini adalah untuk mengajarkan dan menyebarluaskan ilmu Al-Qur'an, cara membaca Al-Qur'an dengan baik dan benar sesuai kaidah ilmu tajwid kepada anak-anak Desa Hambuku Hulu yang kelak akan menjadi penerus umat.

2. Pendanaan

Dana kegiatan program tahsin ini yaitu dana mandiri/pribadi dari mahasiswa. Sehubungan yang diajarkan ilmu tajwid ini adalah tingkat anak-anak, maka proses pembelajaran yang seru dan menarik sangat diperlukan. Salah satunya dengan sistem permainan dan give away (pemberian hadiah bagi anak-anak yang berhasil menjawab pertanyaan dan juga menang dalam permainan).

3. Sasaran

Sasaran dari kegiatan ini adalah anak-anak Desa Hambuku Hulu baik yang sedang ditahap Iqro' ataupun yang sudah sampai pada tingkat Al-Qur'an.

4. Narasumber Kegiatan

Narasumber dari kegiatan ini adalah Mahasiswa KKN STIQ Amuntai. 


\section{B. TINJAUAN PUSTAKA}

1. Pengertian Metode Qira'ati

Metode Qiro'ati merupakan salah satu metode dalam pembelajaran membaca Al-Qur'an yang mana metode ini lebih menekankan pada pendekatan keterampilan proses membaca secara cepat dan tepat, baik pada makhorijul hurufnya maupun bacaan tajwidnya, sehingga akan diperoleh hasil pengajaran yang efektif tahan lama dan dapat dikembangkan sesuai dengan kondisi kemampuan anak didik. ${ }^{3}$

2. Pengertian Tahsin

Tahsin adalah kata arab yang berarti memperbaiki, meningkatkan, atau memperkarya. Tahsin dalam islam mengandung makna bahwa tuntunan agar dalam membaca Al-Qur'an harus benar dan tepat. tahsin menurut bahasa berasal dari 'hassana-yuhassinu' yang artinya membaguskan. Kata ini sering digunakan sebagai sinonim dari kata tajwid yang berasal dari 'jawwada-yujawwidu' apabila ditinjau dari segi bahasa. Tabsin secara bahasa diambil dari kata kerja khassan, yang artinya memperbaiki, atau menghiasi, atau membaguskan, atau memperindah, atau membuat lebih baik dari semula. ${ }^{4}$

3. Pengertian Ilmu Tajwid

Pengertian Tajwid menurut bahasa (ethimologi) adalah: memperindah sesuatu. ${ }^{5}$ Sedangkan menurut istilah, Ilmu Tajwid adalah pengetahuan tentang kaidah serta cara-cara membaca Al-Quran dengan sebaik-baiknya. Tujuan ilmu tajwid adalah memelihara bacaan Al-Quran dari kesalahan dan perubahan serta memelihara lisan (mulut) dari kesalahan membaca. Belajar

3 (Imam Murjito, Pedoman Metode Praktis Pengajaran Ilmu Baca Al-Qur'an Qira'ati (Semarang: Koordinator Pendidikan Al-Qur'an, t.t.), Hal.19.

${ }^{4}$ Hisyam bin Mahrus Ali Al-Makky, Bimbingan Tahsin Tilawah Al-Qur'an (Solo: ZamZam, 2013), hal.45.

${ }^{5}$ Abdullah Asy'ari BA, Pelajaran Ilmu Tajwid (Surabaya: APOLLO, t.t.), hal.7. 
ilmu tajwid itu hukumnya fardlu kifayah, sedang membaca Al-Quran dengan baik (sesuai dengan ilmu tajwid) itu hukumnya Fardlu 'Ain. Dalil Wajib Mempraktekkan Tajwid Dalam Setiap Pembacaan Al-Qur'an :

a. Dalil dari Al-Qur'an.

Firman Allah s.w.t.:

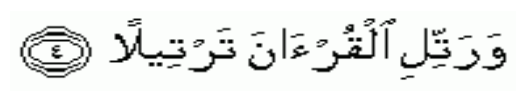

Artinya: Dan bacalah Al-Qur'an dengan tartil. [Q.S. Al-Muzzammil (73): 4].6

Ayat ini jelas menunjukkan bahwa Allah s.w.t. memerintahkan Nabi SAW untuk membaca Al-Qur'an yang diturunkan kepadanya dengan tartil, yaitu memperindah pengucapan setiap huruf-hurufnya (bertajwid).

Firman Allah s.w.t. yang lain :

\section{(بو}

Artinya: Dan Kami (Allab) telab bacakan (Al-Qur'an itu) kepada (Muhammad s.a.w.) secara tartil (bertajwid) [Q.S. Al- Furqaan (25): 32].

b. Dalil dari As-Sunnah.

Dalam hadits yang diriwayatkan dari Ummu Salamah r.a. (istri Nabi SAW.), ketika beliau ditanya tentang bagaiman bacaan dan sholat Rasulullah SAW, maka beliau menjawab:

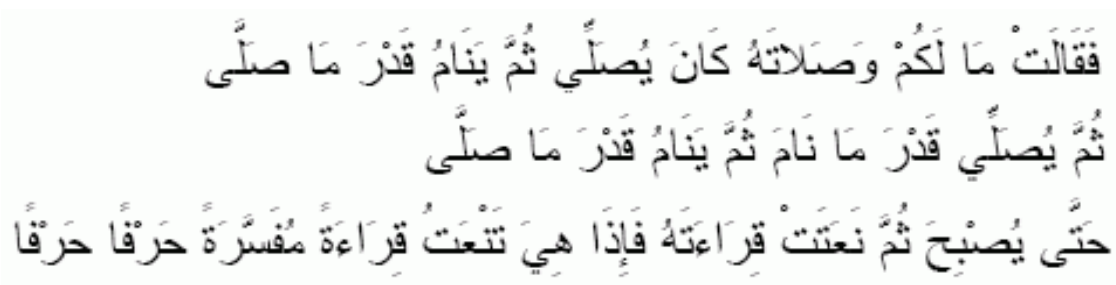

${ }^{6}$ Wawan Sjahrianto, Qur'an Player 2.0.1.0 (Jakarta: Departemen Agama, 2015). 
Artinya: "Ketahuilah bahwa Baginda s.a.w. sholat kemudian tidur yang lamanya sama seperti ketika beliau sholat tadi, kemudian Baginda kembali sholat yang lamanya sama seperti ketika beliau tidur tadi, kemudian tidur lagi yang lamanya sama seperti ketika beliau sholat tadi hingga menjelang shubub. Kemudian dia (Ummu Salamab) mencontobkan cara bacaan Rasulullah s.a.w. dengan menunjukkan (satu) bacaan yang menjelaskan (ucapan) burufburufnya satu persatu." (Hadits 2847 Jamik At-Tirmizi).

\section{HASIL DAN PEMBAHASAN}

Penelitian ini dilaksanakan di rumah belajar mahasiswa KKN STIQ Amuntai. Kelurahan Hambuku Hulu Kecamatan Sungai Pandan Kabupaten Hulu Sungai Utara. Adapun waktu pelaksanaan penelitian ini dilaksanakan mulai dari tanggal 22 Februari sampai 22 Maret 2021.

Jenis penelitian ini menggunakan penelitian kualitatif yang ditujukan untuk mendeskripsikan dan menganalisis fenomena, peristiwa, aktivitas sosial, sikap, kepercayaan, persepsi, pemikiran orang secara individu maupun kelompok, dan beberapa deskripsi untuk menemukan prinsip-prinsip dan penjelasan yang mengarah pada penyimpulan yang sifatnnya induktif. Artinya, peneliti membiarkan permasalahan-permasalahan muncul dari data atau dibiarkan terbuka untuk interpretasi. ${ }^{7}$

Teknik pengumpulan datanya dengan menggunakan metode Observasi. Dalam penelitian ini yang dijadikan objek penelitian adalah anak-anak di rumah belajar KKN STIQ Amuntai.

${ }^{7}$ M. Djunaidi Ghony dan Fauzan AlManshur, Metode Penelitian Kualitatif (Yogyakarta: Ar-Ruzz Media, 2014), hal.28. 
1. Penerapan metode Qiraati pada pembelajaran tajwid dan tahsin di rumah belajar KKN STIQ Amuntai.

Sejak awal program pembelajaran Tajwid dan Tahsin yang berlangsung di rumah belajar Mahasiswa KKN Desa Hambuku Hulu menggunakan metode Qiroati. Metode adalah cara yang digunakan dalam kegiatan nyata agar tujuan yang telah disusun tercapai secara optimal. Metode digunakan untuk merealisasikan strategi yang telah ditetapkan. ${ }^{8}$ Metode Qiroati adalah suatu metode membaca Al-Qur'an yang langsung memasukkan dan mempraktekkan bacaan tartil sesuai dengan kaidah ilmu tajwid.

Metode ini lebih menekankan pada pendekatan keterampilan proses membaca secara cepat dan tepat, baik pada makhorijul hurufnya maupun bacaan tajwidnya, sehingga akan diperoleh hasil pengajaran yang efektif tahan lama dan dapat dikembangkan sesuai dengan kondisi kemampuan anak didik.

Pada saat proses pembelajaran sebenarnya bukan hanya metode qiroati yang digunakan. Akan tetapi, tahsin/metode tahsin juga dipakai dalam mengajarkan Al-Qur'an kepada anak-anak Desa Hambuku Hulu. Sama halnya dengan metode yang lain, metode At-Tahsin adalah suatu kegiatan atau cara yang sudah tersusun secara maksimal untuk memperbaiki atau membaguskan di dalam membaca Alquran. Karena pada intinya semua metode itu memiliki tujuan yang sama, yaitu mengajarkan dasar-dasar huruf hijaiyah, tajwid, panjang pendek di dalam Alquran.

2. Proses Pembelajaran di Rumah Belajar KKN STIQ Amuntai

Ketika seseorang atau sebuah lembaga mengajarkan suatu pelajaran, diperlukan adanya metode- metode pembelajaran yang bervariasi, hal ini dilakukan agar siswa tidak bosan dalam mengikuti kegiatan belajar selama berlangsung. Selain metode, media pembelajaran juga sangat penting. Seperti dengan sistem permainan, belajar sambil bermain.

${ }^{8}$ Wina Sanjaya, Strategi Pembelajaran Berorientasi Standar Proses Pendidikan. (Jakarta: Prenadia Media, 2006), hal.147. 
Proses pembelajaran dimulai dengan membaca do'a-do'a kurang lebih 5 menit, kemudian diberi semangat dengan yeal-yeal dan lagu-lagu yang tentunya asik dan masih berkenaan dengan memulai pembelajaran. Setelah anak-anak sudah semangat, fokus dan siap belajar. Maka, di tuliskanlah di papan tulis deretan huruf-huruf hijaiyah. Kemudian secara bersama-sama melantunkan huruf-huruf tersebut yang dibimbing oleh Mahasiswa KKN. Sehubungan yang ikut belajar juga masih ada yang TK Kecil, maka cara ini lumayan membakar semangat mereka dalam belajar.

Setelah selesai, kemudian dituliskan 3-4 huruf hijaiyah dengan disertai baris yang fathah, kasroh dan dhommah. Di contohkan terlebih dahulu lalu anak-anak diminta mengulangi secara bersamaan kemudian selanjutnya secara satu persatu diminta maju ke depan untuk membaca huruf-huruf hijaiyah yang sudah dipelajari. Terkadang bisa juga dengan sistem perkelompok. Jadi satu orang Mahasiswa memegang 4-5 orang anak-anak untuk di evaluasi makharijul huruf yang baru saja selesai diajarkan. Setelah selesai mempraktekkan lalu anak-anak menuliskan huruf-huruf hijaiyah tersebut di buku tulis masing-masing untuk diberi penilaian menulis. Terakhir, pembelajaran di tutup dengan lantunan surah dan do'a-do'a.

3. Faktor-faktor Penunjang dalam Proses Pembelajaran di Rumah Belajar KKN STIQ Amuntai

a. Tempat

Selama proses pembelajaran berlangsung, kami mengadakannya di rumah belajar yang notabennya itu adalah Posko mahasiswa KKN. Sehubungan rumah yang ditempati itu cukup luas, jadi sangat mendukung dalam menampaung anak-anak yang lumayan banyak. Sekalipun demikian, jika terkadang anak-anak yang datang banyak, maka pembelajaran dengan sistem perkelompok agar tetap bisa menjaga protokol kesehatan. 
b. Media pembelajaran

Media yang digunakan adalah papan tulis, spidol dan beberapa buah buku tahsin dan pembelajaran tajwid. Jadi, materi-materi ilmu tajwid dituliskan di papan tulis, kemudian dijelaskan.

4. Faktor-faktor Penghambat dalam Proses Pembelajaran di Rumah Belajar KKN STIQ Amuntai

a. Orang Tua

Salah satu faktor yang sedikit menghambat proses pembelajaran adalah kurangnya dukungan orang tua terhadap anak-anaknya yang ingin belajar tajwid di Rumah Belajar KKN STIQ Amuntai. Karena ada anak-anak yang awal-awal ikut belajar kemudian berhenti mengikuti kegiatan. Ketika ditanya mereka mengatakan bahwa orang tuanya tidak mengizinkan, ada juga yang mengatakan bahwa dia disuruh menjaga adik mereka.

b. Minat dan Motivasi Anak

Selama proses pembelajaran berlangsung minat dan motivasi anak juga sangat berpengaruh.

c. Sarana Pembelajaran

Faktor lain yang ikut menghambat proses kegiatan ini ialah kurangnya fasilitas seperti meja belajar, jadi dengan terpaksa mereka belajar dan menulis tanpa menggunakan alas/meja.

\section{SIMPULAN DAN SARAN}

Penelitian ini yang dilakukan oleh mahasiswa STIQ Rakha Amuntai sebagai tugas akhir dari kuliah kerja nyata $(\mathrm{KKN})$. Kegiatan ini selain sebagai tugas akhir dari KKN juga sebagai wadah menyalurkan ilmu Al-Qur'an kepada anak-anak di desa Hambuku Hulu yang telah di dapat di kampus STIQ, Dalam hal ini Pendidikan Al- 
Qur'an adalah pendidikan paling utama yang harus diajarkan kepada setiap manusia. Baik itu untuk dirinya sendiri, keluarga, teman, maupun yang lainnya. pembelajaran AlQur'an itu sangatlah penting.

Semoga kedepannya anak-anak didesa tersebut mampu membaguskan bacaannya karena dalam membaca ayat-ayat suci Al-Qur'an itu bukan hanya sekedar membaca. Melainkan juga harus sesuai dengan kaidah ilmu tajwid dan tahsin.

\section{UCAPAN TERIMA KASIH}

Penulis mengucapkan terimakasih yang tak terhingga kepada orangtua peserta didik yang sudah mempercayai kami dalam melakukan pembelajaran tahsin dan tajwid di rumah belajar Pokso KKN Hambuku Hulu dan tidak lupa juga kami ucapkan terimakasih kepada Mualim Ridhatullah Assya'bani M.Ag selaku DPL Desa Hambuku Hulu yang telah membimbing kami dalam melakukan kegiatan ini.

\section{DAFTAR RUJUKAN}

Al-Makky, Hisyam bin Mahrus Ali. Bimbingan Tabsin Tilawah Al-Qur'an. Solo: ZamZam, 2013.

BA, Abdullah Asy'ari. Pelajaran Ilmu Tajwid. Surabaya: APOLLO, t.t.

Ghony, M. Djunaidi, dan Fauzan AlManshur. Metode Penelitian Kualitatif. Yogyakarta: Ar-Ruzz Media, 2014.

iri, Abu Bakar Jabir al-Jaza. Minhajul Muslim::Konsep Hidup Ideal dalam Islam. Jakarta: Darul Haq, 2011.

Murjito, (Imam. Pedoman Metode Praktis Pengajaran Ilmu Baca Al-Qur'an Qira'ati. Semarang: Koordinator Pendidikan Al-Qur'an, t.t.

Ramayulis. Ilmu Pendidikan Islam. Jakarta, 2012. 
Sanjaya, Wina. Strategi Pembelajaran Berorientasi Standar Proses Pendidikan. Jakarta: Prenadia Media, 2006.

Sjahrianto, Wawan. Qur'an Player 2.0.1.0. Jakarta: Departemen Agama, 2015. 
